\title{
Reconstruction of open wounds as a complication of spinal surgery with flaps: a systematic review
}

\author{
Lee Onn Chieng, BS, ${ }^{1}$ Zachary Hubbard, BS, ${ }^{1}$ Christopher J. Salgado, MD, ${ }^{2}$ \\ Allan D. Levi, MD, PhD, ${ }^{3}$ and Harvey Chim, MD² \\ ${ }^{1}$ University of Miami Miller School of Medicine; and ${ }^{2}$ Division of Plastic Surgery and ${ }^{3}$ Department of Neurosurgery, University of \\ Miami Miller School of Medicine, Miami, Florida
}

\begin{abstract}
OBJECT A systematic review of the available evidence on the prophylactic and therapeutic use of flaps for the coverage of complex spinal soft-tissue defects was performed to determine if the use of flaps reduces postoperative complications and improves patient outcomes.

METHODS A PubMed database search was performed to identify English-language articles published between 1990 and 2014 that contained the following phrases to describe postoperative wounds ("wound," "complex back wound," "postoperative wound," "spine surgery") and intervention ("flap closure," "flap coverage," "soft tissue reconstruction," "muscle flap").

RESULTS In total, 532 articles were reviewed with 17 articles meeting the inclusion criteria of this study. The risk factors from the pooled analysis of 262 patients for the development of postoperative complex back wounds that necessitated muscle flap coverage included the involvement of instrumentation (77.6\%), a previous history of radiotherapy $(33.2 \%)$, smoking (20.6\%), and diabetes mellitus (17.2\%). In patients with instrumentation, prophylactic coverage of the wound with a well-vascularized flap was shown to result in a lower incidence of wound complications. One study showed a statistically significant decrease in complications compared with patients where prophylactic coverage was not performed ( $20 \%$ vs $45 \%$ ). The indications for flap coverage after onset of wound complications included hardware exposure, wound infection, dehiscence, seroma, and hematoma. Flap coverage was shown to decrease the number of surgical debridements needed and also salvage hardware, with the rate of hardware removal after flap coverage ranging from $0 \%$ to $41.9 \%$ in 4 studies.
\end{abstract}

CONCLUSIONS Prophylactic coverage with flaps in high-risk patients undergoing spine surgery reduces complications, while therapeutic coverage following wound complications allows the salvage of hardware in the majority of patients.

http://thejns.org/doi/abs/10.3171/2015.7.FOCUS15245

KEY WORDS spine; back flaps; complications of spinal surgery

$\mathrm{P}$ OSTERIOR soft-tissue defects in the cervical, thoracic, and lumbar regions resulting from the complications of spinal surgery are a difficult challenge to manage. Conditions such as osteomyelitis, extensive tumor resection, congenital anomalies, trauma, repeated surgery, and radiation therapy can all lead to chronic wounds that are prone to contamination. These result in soft-tissue defects that negatively affect patient outcomes. Coverage of back wounds becomes even more critical when hardware is exposed, as hardware is essential for both spinal stability and neurological function.

Such scenarios become increasingly demanding in patients with certain risk factors for postoperative surgical site infection following lumbar arthrodesis such as alcohol abuse, smoking, advanced age, corticosteroid use, malnutrition, and prolonged hospitalization. ${ }^{6,31}$ Koutsoumbelis et al. also identified diabetes, obesity, osteoporosis, and chronic obstructive pulmonary disease as significant patient-related risk factors that may affect the ability of the wound to heal. ${ }^{21}$

Surgeries to resect spinal neoplasms have resulted in more radical resections of local tissue. This has led to more patients with decreased wound-healing capacity. Various factors such as previous radiation therapy or chemotherapy can contribute to the increased need for softtissue coverage. These patients are at high risk for postsur-

ABBREVIATION VAC $=$ vacuum-assisted closure. 
gical wound complications that may result in the exposure of vital neural structures and prosthetic materials. ${ }^{7}$

The use of musculocutaneous flaps can provide a solution for such complex reconstructive challenges. Musculocutaneous flaps are known to actively inhibit bacterial growth in both moderate and minimally contaminated wounds. ${ }^{27}$ Blood flow is significantly higher in musculocutaneous flaps when compared with fasciocutaneous flaps or skin controls. ${ }^{11}$ This increased blood flow expedites oxygen delivery, which allows the tissue to mount an enhanced inflammatory response to the bacteria present within the surgical site. The increased blood flow provides an oxygen-rich environment, which then heightens the production of hydrogen peroxide and superoxide by leukocytes, accelerating bacterial elimination. ${ }^{11}$

Calderon et al. demonstrated that the greater deposition of tissue in the space covered by the flap contributes to the marked decrease in the bacterial concentration. This is a result of higher collagen and hydroxyproline content within the wound, ultimately decreasing the space in which bacteria may proliferate. ${ }^{5}$

Local tissue is a preferred source for musculocutaneus flaps, as it minimizes the mobilization required for coverage and replaces the defect with similar tissue. However, this is not always possible due to limited local tissue availability, particularly after extensive radiation or resection. For this reason, the paraspinous flap is the most common approach; however, other strategies use tissue from the gluteus maximus, rectus abdominis, and latissimus dorsi muscles. ${ }^{3,7}$

In patients with instrumentation, prophylactic coverage of the wound with a well-vascularized flap has been shown to result in a lower incidence of major wound complications., ${ }^{72}$ Providing prophylactic soft-tissue coverage can aid in healing and minimize major complications when difficult wound closure is anticipated. ${ }^{10,13}$ This is very useful in patients who have had previous radiation therapy, chemotherapy, or previous failed surgeries and may also be indicated for patients with comorbidities such as diabetes who are at increased risk of infection. In the presence of a significant amount of dead space, a muscle flap may be useful for filling the space and decreasing the risk of seroma, hematoma, and surgical site infection. The therapeutic use of flaps for the coverage of complex spinal wounds is also widely practiced, particularly in the presence of exposed hardware. The majority of the available literature on this subject consists of retrospective case series and case reports. Hence, the aim of this study was to perform a systematic review of the available evidence on the prophylactic and therapeutic use of flaps for the coverage of complex soft-tissue defects over the spine in order to determine if the use of flaps reduces postoperative complications and improves patient outcomes.

\section{Methods \\ Study Selection}

With compliance with the PRISMA (Preferred Reporting Items for Systematic Reviews and Meta-Analyses) guidelines, a PubMed database search was performed to identify English-language literature published between
1990 and 2014. Combinations of the following phrases that describe postoperative wound ("wound," "complex back wound," "postoperative wound," "spine surgery") and intervention ("flap closure," "flap coverage," "soft tissue reconstruction," "muscle flap") were used to conduct the search. Two reviewers (L.O.C. and Z.H.) independently performed each step of the study selection process. Additional articles were located by cross-referencing articles encountered initially through the PubMed searches. Inclusion criteria comprised case reports, case series, retrospective studies, prospective reports, and clinical trials that reported flap usage following spine surgery. Reviews, cadaveric studies, editorials, and commentaries were excluded. Studies that reported nonsurgical wound complications such as decubitus ulcers that were not directly associated with spine surgery were excluded.

\section{Data Extraction and Analysis}

After the initial screening using the previously mentioned criteria, the 2 reviewers independently assessed the quality and methodology of each study. The articles were further analyzed based on patient population, interventions, associated outcomes, and complications. If there was disagreement regarding the potential relevance of each study, both reviewers discussed the differences with each other until a consensus was reached. The standardized reporting scheme provided by the North American Spine Society was used to assess the level of evidence of the included articles (https://www.spine.org/Portals/0/ Documents/ResearchClinicalCare/LevelsOfEvidence. pdf). Data from different studies were pooled to determine the distributions of certain parameters. Descriptive statistics was calculated using SPSS software (version 22.0, IBM).

\section{Results \\ Search Results}

Our PubMed search yielded 532 articles for screening, and, with the application of our inclusion criteria, we narrowed down the results to 17 articles (3 case reports, ${ }^{8,14,21} 5$ case series, ${ }^{4,9,16,20,30}$ and 9 retrospective studies $^{7,10,13,17,24-26,28,32}$ ). The detailed study selection flowchart is shown in Fig. 1. There were no prospective or comparative studies found by our searches.

\section{Baseline Characteristics}

Table 1 summarizes 17 studies in which 403 patients were included. The mean age was 61.7 years old (range 1-90 years), and $57 \%$ of patients were male. The average length of follow-up was 17.3 months (range 0.7-115 months). Before receiving flap coverage, all patients underwent spine surgery for their index diagnosis, which comprised spine deformity, degenerative conditions, or neoplasms. The majority of the patients (72\%) had therapeutic flap surgery, while approximately one-quarter of them $(28 \%)$ had prophylactic flap surgery.

\section{Risk Factors for the Development of Postoperative Wounds}

Four studies extensively investigated the potential risk 
factors for postoperative complex back wound that necessitated muscle flap coverage. ${ }^{7,13,17,25}$ A total of 262 patients were pooled to analyze the overall breakdown of various potential contributing factors. The greatest potential factor was involvement of instrumentation (77.6\%). Other factors included previous history of radiotherapy (33.2\%), smoking (20.6\%), and diabetes mellitus (17.2\%). Chang et al., in their multivariate analysis of 92 spinal oncology patients, demonstrated an OR of $3.76(\mathrm{p}=0.085)$ for developing complex wounds when spinal hardware was placed in the spine. ${ }^{7}$ In the same study, the authors observed a higher risk (OR 2.94, $\mathrm{p}=0.06$ ) of developing complex wounds among patients with spine instrumentation who had 2 or more surgeries at the same site as compared with patients who received flap coverage after their first surgery.

Surgical site infection was the greatest indicator for flap usage. Hultman et al. found that $84 \%$ of patients required debridement and reconstruction due to wound infection. ${ }^{17}$ Mericli et al. reported a similar number, $81.5 \%$, in their retrospective study of 92 patients. ${ }^{25}$ Wound cultures typically identified Staphylococcus aureus, S. epidermidis, and Enterococcus. Less common organisms included Candida, Klebsiella, Actinobacteria, Pseudomonas, Bacteroides, Prototheca, Proteus, and Coccidioides., ${ }^{40,16,17,24,26}$ Six patients were found to have polymicrobial infections. ${ }^{16,17}$

\section{Flap Type and Location}

As demonstrated in Fig. 2, the most common flaps used were paraspinal muscle (56\%) followed by latissimus (19\%) and trapezius (15\%) flaps. All of the flaps were pedicled or rotational in nature, except for $3 \%$ of the total that comprised free latissimus flaps (3\%). The remaining pedicled flaps included omental and superior gluteal flaps. Two or more flaps were used in a small proportion of patients. For instance, depending on the level and size of the wound, a combination of paraspinal and superior gluteal flaps were typically employed for coverage at the lower lumbar area, while a combination of paraspinal and trapezius flaps was used for cervical and thoracic level coverage. In total, $45 \%$ of the flaps were used for closure at the thoracic region, while the remaining $36 \%$ and $19 \%$ were employed at the lumbar and cervical levels, respectively.

When looking at the types of flaps used by anatomical location, at the lumbosacral level gluteal flaps were the most commonly used followed by the paraspinal muscle flaps. At the thoracic level, latissimus dorsi flaps and paraspinal muscle flaps were the most commonly used. Trapezius flaps were less commonly used in this area. At the cervical level, paraspinal muscle flaps were the most commonly used, followed by latissimus and trapezius flaps.

\section{Indications and Reasons to Undergo a Flap Coverage Procedure}

Five studies with a total of $111(28 \%)$ patients received prophylactic muscular flaps for immediate closure following spine surgery when it was felt that there was a high risk of wound-healing problems. , $^{73,19,28,33}$ Four of these 5 studies carried out a comparative analysis with a control group in which closure was delayed. The decision to provide a prophylactic flap was mainly made based on the identification of the patient's major risk factors, which included

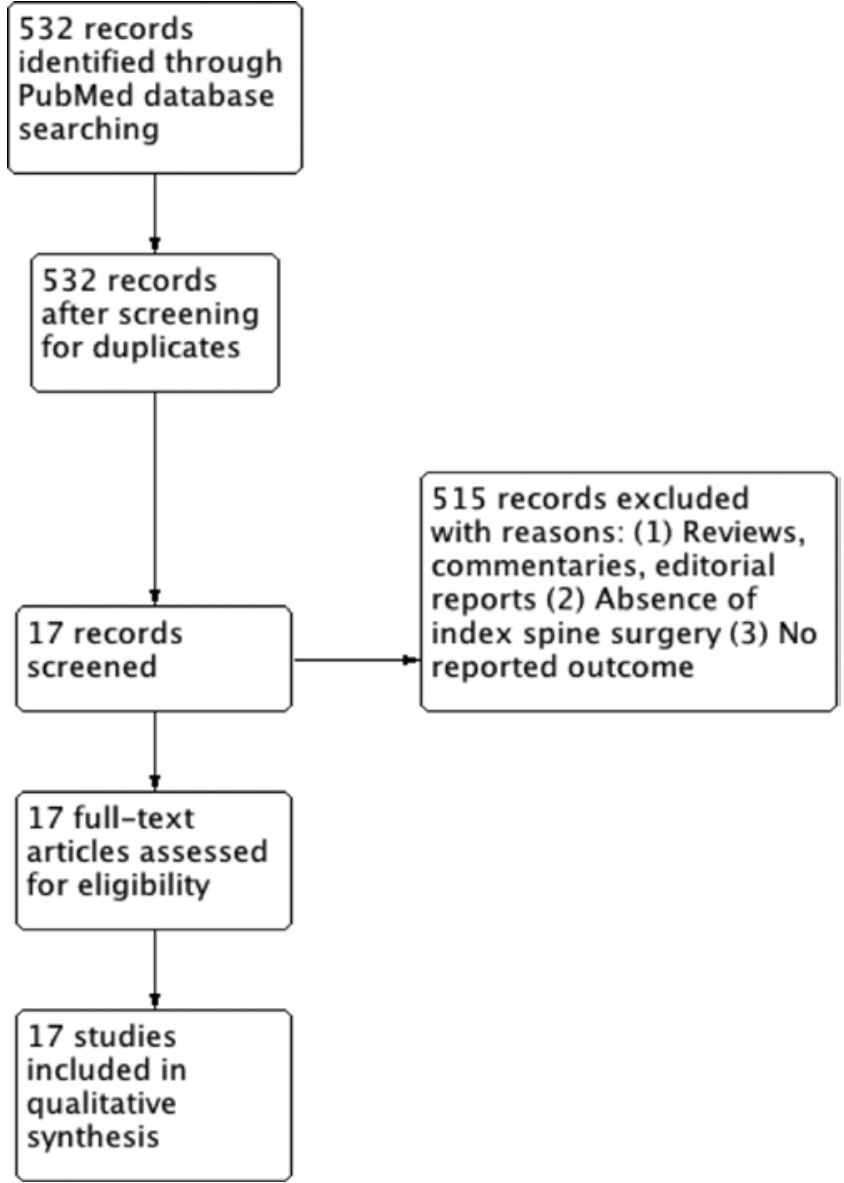

FIG. 1. Methodology for selecting articles for this systematic review.

instrumentation (56.2\%), irradiation (46.9\%), and previous surgery $(34.3 \%)$. There was a statistically significant difference in the incidence of complications in patients who underwent prophylactic soft-tissue reconstruction with instrumentation of the spine for spinal neoplasms compared with those who did not ( $20 \%$ vs $45 \%)^{7}$ Another study $^{13}$ found that prophylactic reconstruction with muscle flaps resulted in a low major complication rate of $12 \%$, with no patients requiring removal of hardware.

As for secondary closure for treating complex back wounds, the mean time interval from spine surgery to the flap reconstruction was 4.7 months. ${ }^{7}$ The most common indication was wound infection $(81.5 \%)$ followed by wound dehiscence (17.4\%), seroma (10.9\%), and hematoma (6.5\%) as reported by Mericli et al. in their retrospective cohort of 92 patients..$^{25}$ Meanwhile, Chang et al. reported hardware exposure (40.9\%) as the most common indication among patients with instrumentation.?

\section{Clinical Outcomes}

Salvage of hardware was the most important parameter for assessing flap surgery outcome in patients with exposed instrumentation. Four studies demonstrated that the rate of hardware removal varied from $0 \%$ to $41.9 \%$ in patients with instrumentation., ${ }^{7,13,17,25}$ The spinal hardware was successfully salvaged and retained with flap coverage in the remaining majority of patients with spinal implants. 


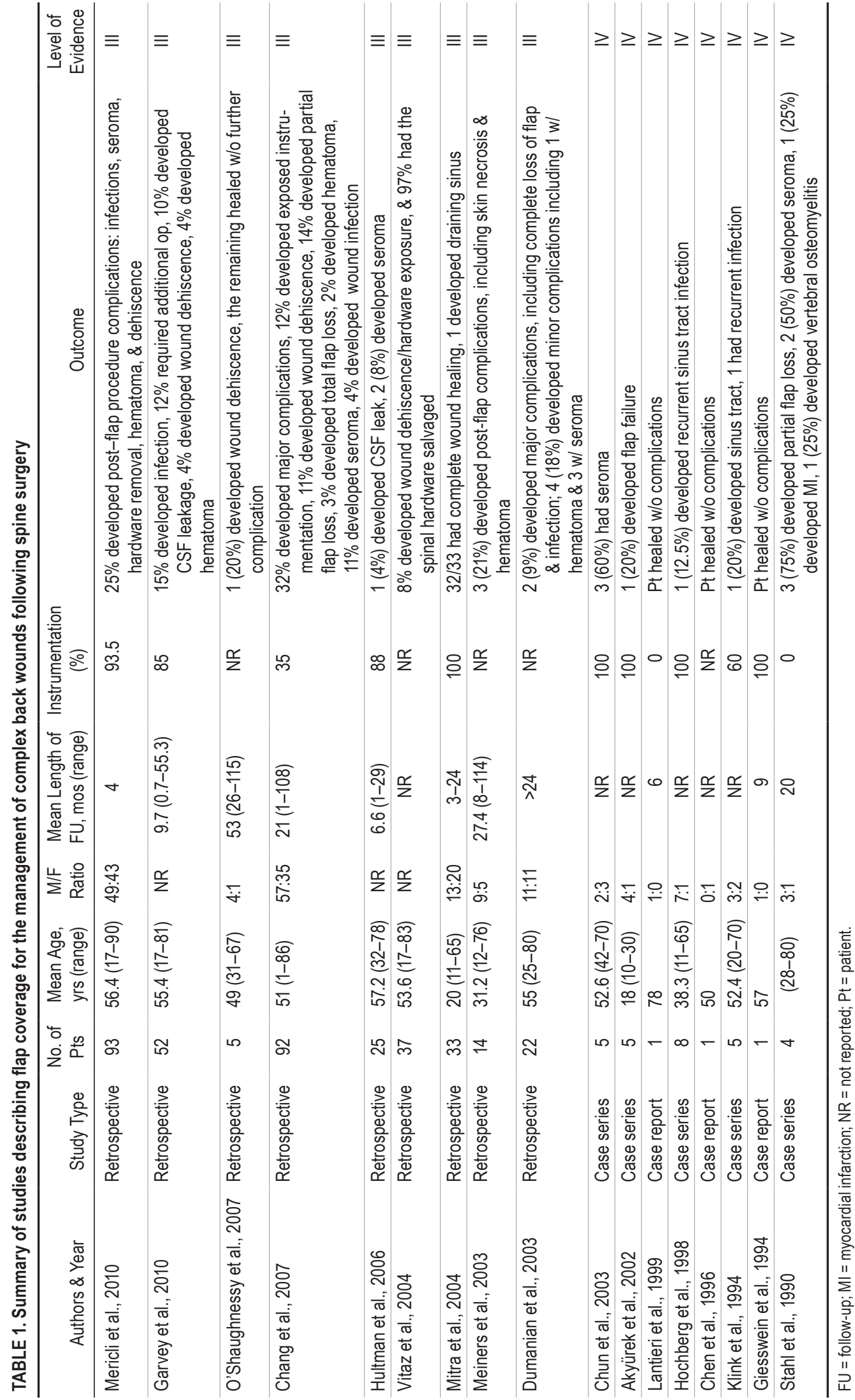




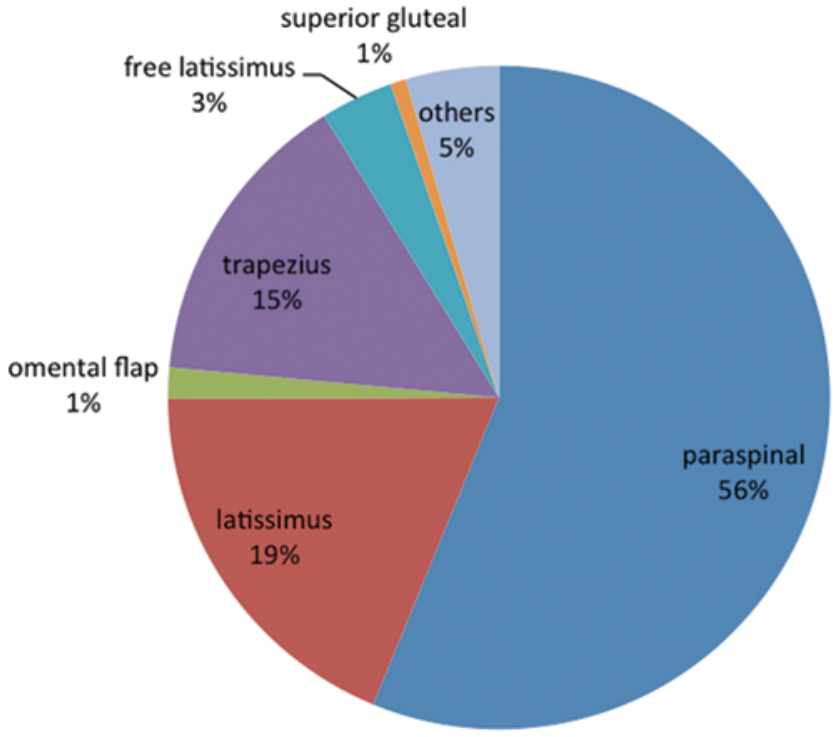

FIG. 2. Distribution of flaps used for the coverage of complex spinal wounds. The most common flap used was paraspinal (56\%), followed by latissimus dorsi (19\%).

One study reported that the average length of hospital stay was 22.8 days in 92 patients with paraspinal flap placement. ${ }^{25}$

\section{Complications Following Flap Coverage}

Several complications were reported by the 5 major representative studies, which developed after onset of the flap coverage procedure. However, not all of these complications were directly related to the flap placement. The detailed breakdown of the major complications is demonstrated in Table 2.

While flap failure was not common, Hultman et al. observed skin necrosis in 1 patient who had a unilateral paraspinal flap turnover flap. ${ }^{17}$ In addition, of 14 patients who had latissimus flap surgery, 3 developed skin necrosis. All were successfully treated with skin grafting. Dumanian et al. also reported the "loss" of 1 patient's superior gluteal flap as a result of a venous thrombosis. ${ }^{10}$ Of the 92 patients reported by Chang et al., 3 had total flap loss and an additional 13 patients had partial flap loss.?

\section{Discussion}

\section{Prevention Strategies}

Preventive measures may prevent wound complications that require coverage. These strategies include: 1) Waiting the appropriate amount of time between the index surgery and postoperative radiation therapy: the importance of wound healing before starting radiation therapy cannot be overemphasized. 2) Providing adequate nutrition: albumin and prealbumin should be routinely checked to assess this. 3) Use of vitamins. 4) Using minimally invasive techniques for spinal reconstruction, such as percutaneous pedicle screws or minimally invasive lateral approaches for corpectomy, and decreasing the need for long incisions, which may develop complications. 5) Administering prophylactic antibiotics to patients at high risk of developing infection.

In addition, as an alternative to major reconstruction procedures involving flaps, spine surgeons have attempted to use various prophylactic interventions to prevent surgical site infection. The intraoperative local administration of vancomycin powder before closure has been proven to be protective by decreasing the incidence of surgical site infection. A recent meta-analysis of 5102 patients demonstrated a robust relative risk reduction of $68 \%$ in developing surgical site infection, especially in the instrumentation group $(\mathrm{p}=0.023) .{ }^{19}$ Vacuum-assisted closure (VAC) technology can play a role in the closure of an open wound by reducing dead space and hence reducing complications such as seroma, CSF leakage, or hematoma. A VAC dressing placed over the incision of a closed wound up to postoperative Day 3 has been shown to improve outcomes by removing excess fluid, improving blood flow, and hence increasing the stimulation of granulation tissue formation. ${ }^{1}$ Another postoperative preventative measure is hyperbaric oxygen therapy, which may be employed to increase oxygen tension at the surgical site, augment bactericidal activity, and even stimulate angiogenesis in irradiated tissue. ${ }^{23}$ Inanmaz et al. described a reduction in the infection rate of complex wounds following scoliosis surgery through the use of hyperbaric oxygen prophylaxis..$^{18}$

\section{Management Strategies}

Complicated back wounds often require aggressive care and multiple debridements. When a wound has not healed after conservative treatment with VAC dressings or multiple debridements, flap coverage may be considered. Patients should ideally have their nutrition optimized and comorbidities, such as diabetes mellitus and smoking, under control. Typically, this is assessed through blood tests, where albumin should be $>2.0 \mathrm{~g} / \mathrm{dl}$ and prealbumin $>20$ $\mathrm{mg} / \mathrm{dl}$. Ideally the wound bed will be clean and granulat-

TABLE 2. Complications following flap coverage

\begin{tabular}{lccccccc}
\hline & \multicolumn{7}{c}{ No. of Post-Flap Coverage Complications (\%) } \\
\cline { 2 - 8 } Authors \& Year & Revision Op/Reop & $\begin{array}{c}\text { Wound } \\
\text { Infection }\end{array}$ & $\begin{array}{c}\text { Wound } \\
\text { Dehiscence }\end{array}$ & Seroma & $\begin{array}{c}\text { Hardware } \\
\text { Exposure }\end{array}$ & Hematoma & CSF Leak \\
\hline Mericli et al., 2010 & NR & $12(13)$ & NR & $11(12)$ & NR & $1(1)$ & NR \\
\hline Garvey et al., 2010 & $6(12)$ & $8(15)$ & $2(4)$ & $2(4)$ & $1(2)$ & $2(4)$ & $5(10)$ \\
\hline Chang et al., 2007 & $29(32)$ & $4(4)$ & $10(11)$ & $10(11)$ & $11(12)$ & $2(2)$ & NR \\
\hline Hultman et al., 2006 & $2(8)$ & NR & NR & $2(8)$ & NR & NR & $1(4)$ \\
\hline Vitaz et al., 2004 & $1(2.7)$ & NR & $1(2.7)$ & NR & $1(2.7)$ & NR & NR \\
\hline
\end{tabular}


ing with no evidence of active infection. Exposed hardware that may harbor biofilm may be switched out for new hardware at the same time as flap coverage.

Stahl et al. ${ }^{30}$ described a 4-pillar concept of debridement, in which 4 columns of support (comprising the paravertebral musculature, posterior element and its related ligaments, facet joint as well as its neighboring ligaments, and the anterior vertebral column) need to be preserved. Losing 2 or more of such "pillars" may result in chronic and acute spinal deformity. While the majority of patients reported in the literature had hardware implanted, the decision to retain or remove the hardware when exposed remains controversial. Removal might result in spinal column instability, while retention of hardware could potentially further increase the amount of dead space as well as delay wound healing. Two studies demonstrated robust outcomes in terms of complete $(100 \%)$ spinal hardware salvage when muscular flap coverage was performed.,13 However, in another 2 studies, Mericli et al. ${ }^{25}$ and Hultman et al. ${ }^{17}$ reported hardware removal rates of $41.9 \%$ and $22.7 \%$, respectively. The main reasons that prompted the spine surgeons to remove the hardware were the development of severe hematoma, infection, seroma, and dehiscence. Conversely, Mericli et al., in the same study, observed significantly higher complication rates $(34.6 \% ; \mathrm{p}=0.02)$ and longer hospital stays when spinal hardware was removed prior to the flap procedure. The positive outcome of flap coverage was also demonstrated by a reduced number of surgical debridements. Vitaz et al. reported an average of 1.4 debridement operations performed in the flap coverage group as compared with the average of 4.7 procedures needed in the nonflap coverage group reported by Glassman et al. ${ }^{15,32}$

Although there were no direct comparisons of the recovery rate based on flap type for coverage at specific regions, several intraoperative measures, including regional expansion of the wound, separation of the flap from a primary blood source, and temporary reduction in circulation, have been associated with flap failure and the complication rate. ${ }^{2,12,29}$ Furthermore, scar tissue formation resulting from previous surgery or infection may limit the availability of viable flaps. Nonetheless, these could be overcome by using a combination of 2 or more flaps or by transferring a free flap to the site of the defect.

Few studies looked into the role of prophylactic flaps immediately following index spine surgery to prevent complex back wound in a high-risk patient group. Chang et al. and Garvey et al. advocated the use of prophylactic flap surgery in their spinal neoplasm group as the patients had multiple major risk factors, e.g., irradiation and instrumentation. They observed a reduced incidence of complex back wounds when compared with the control group with a delayed flap procedure (after the onset of a complex wound). ${ }^{7,13}$

\section{Regional and Anatomical Approaches}

The options for covering a spinal defect depend on the level and location of the wound. In all areas, advancement or turnover paraspinal muscle flaps are good options for small wounds. In the cervical and upper thoracic region, trapezius and latissimus dorsi flaps are good options for coverage. In the lower thoracic and lumbar regions, a re- verse turnover latissimus dorsi flap based on paraspinal segmental perforators from the intercostal arteries can be used. In the lumbar region, gluteus maximus or superior gluteal artery perforator flaps can be used for coverage. For very large defects or when local flaps are not available due to previous surgery or radiation, free flaps are the last resort for coverage. Case examples are presented below.

\section{Case 1: Coverage of A Lower Cervical and Upper Thoracic Wound With Latissimus Dorsi Myocutaneous Flap}

A 70-year-old female with metastatic breast cancer to the spine underwent thoracic laminectomy and had postoperative radiation for 5 weeks. The patient developed progressive thoracic kyphosis and a nonhealing infected open wound over the lower cervical and upper thoracic spine with extensive radiation dermatis around the wound (Fig. 3A). Six months after the initial surgery, she underwent revision C7-T4 laminectomy and C7-T7 fusion. Coverage was performed with a pedicled myocutaneous latissimus dorsi flap based on the thoracodorsal vessels. At 8 weeks postoperatively, the wound was completely healed (Fig. 3B).

\section{Case 2: Coverage of Thoracolumbar Wound With Bilateral Turnover Latissimus Dorsi Muscle Flaps}

A 54-year-old male paraplegic due to a motor vehicle accident 30 years prior had multiple surgeries for spinal stabilization with concomitant Charcot joint. Following T12-L4 fusion, he developed an open wound and exposed hardware (Fig. 4A) with drainage that required multiple debridements over a 6-month period. He subsequently developed spinal dislocation at the L2-3 level (Fig. 4B) and was brought to the operating room for a iliac crest fusion. Figure $4 \mathrm{C}$ shows the wound after the placement of instrumentation. Bilateral reverse latissimus dorsi flaps were elevated (Fig. 4D) and turned over to cover the exposed hardware (Fig. 4E). The skin was closed primarily (Fig. 4F).

\section{Limitations}

There were several limitations to this systematic review.
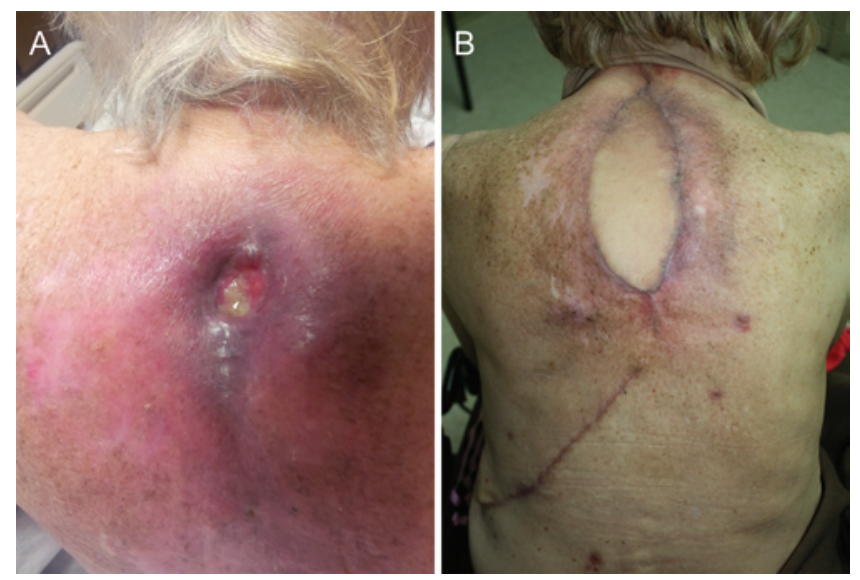

FIG. 3. Coverage of lower cervical and upper thoracic wound with latissimus dorsi myocutaneous flap. A: Extensive radiation dermatitis is present with an infected sinus tract leading down to the vertebrae. B: Eight-week postoperative result showing a well-healed wound. 


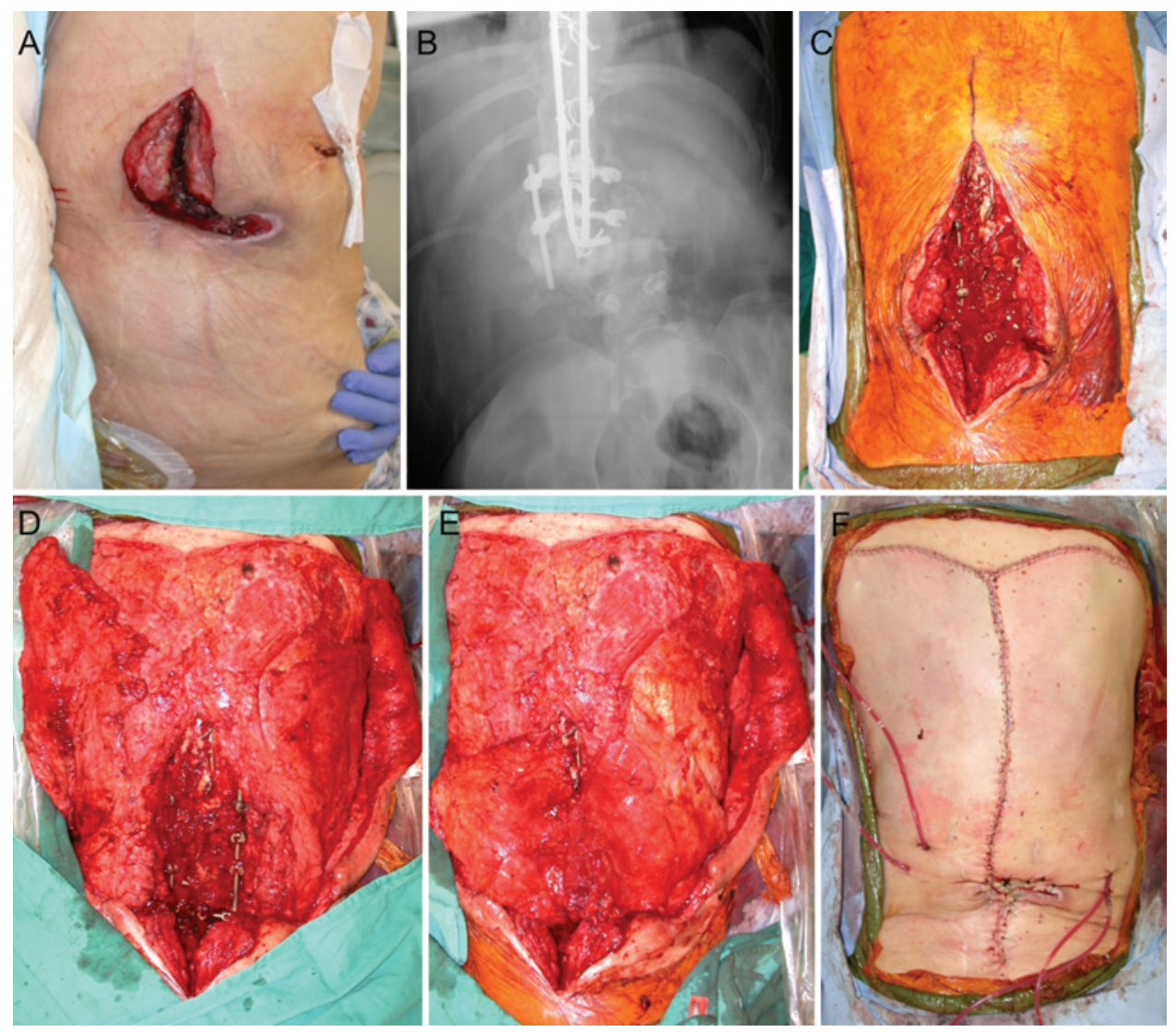

FIG. 4. Coverage of a thoracolumbar wound using bilateral turnover latissimus dorsi muscle flaps. A: Lumbar wound with exposed hardware. B: Radiograph showing spinal dislocation at the L2-3 level. C: Thoracolumbar wound after the placement of hardware. D and E: Turnover latissimus dorsi flaps were elevated bilaterally (D) and cover exposed hardware (E). F: The skin was closed primarily.

Generalizing results is challenging because most of the published literature is limited to case reports, case series, and retrospective analyses of small patient populations with low levels of evidence. There were no studies with Level I or II evidence. There were no direct comparisons between flap coverage groups and conventional treatment groups. Significant heterogeneity between studies, including patient populations, surgeon's management approaches, and outcome evaluations, was also noted. Nevertheless, the available data does provide useful guidelines on the indications for and results of flap coverage.

\section{Conclusions}

Taken together, flap coverage has been shown to reduce infection and promote complex wound healing. Spine surgeons should advocate prophylactic coverage with muscle or fasciocutaneous flaps in patients with the risk factors for postoperative complications. This might potentially reduce the total cost of care by reducing the rate of complications, reoperation, and hence the length of hospitalization. Larger studies with comparative cohorts are needed to further characterize these beneficial outcomes.

\section{References}

1. Adogwa O, Fatemi P, Perez E, Moreno J, Gazcon GC, Gokaslan ZL, et al: Negative pressure wound therapy reduces incidence of postoperative wound infection and dehiscence after long-segment thoracolumbar spinal fusion: a single institutional experience. Spine J 14:2911-2917, 2014

2. Ahluwalia R, Martin D, Mahoney JL: The operative treatment of pressure wounds: a 10-year experience in flap selection. Int Wound J 7:103-106, 2010

3. Aho JM, Laungani AT, Herbig KS, Wong C, Kirchoff RW, Saint-Cyr M: Lumbar and thoracic perforators: vascular anatomy and clinical implications. Plast Reconstr Surg 134:635e-645e, 2014

4. Akyürek M, Şafak T, Alanay A, Acaroğlu E, Keçik A: Immediate debridement and coverage of exposed spinal hardware with muscle flaps. Eur J Plast Surg 25:202-208, 2002

5. Calderon W, Chang N, Mathes SJ: Comparison of the effect of bacterial inoculation in musculocutaneous and fasciocutaneous flaps. Plast Reconstr Surg 77:785-794, 1986

6. Capen DA, Calderone RR, Green A: Perioperative risk factors for wound infections after lower back fusions. Orthop Clin North Am 27:83-86, 1996

7. Chang DW, Friel MT, Youssef AA: Reconstructive strategies in soft tissue reconstruction after resection of spinal neoplasms. Spine (Phila Pa 1976) 32:1101-1106, 2007

8. Chen HC, Chen HH, Chen WJ, Tang YB: Chronic osteomyelitis of the spine managed with a free flap of latissimus dorsi. A case report. Spine (Phila Pa 1976) 21:2016-2018, 1996

9. Chun JK, Lynch MJ, Poultsides GA: Distal trapezius musculocutaneous flap for upper thoracic back wounds associated with spinal instrumentation and radiation. Ann Plast Surg 51:17-22, 2003 
10. Dumanian GA, Ondra SL, Liu J, Schafer MF, Chao JD: Muscle flap salvage of spine wounds with soft tissue defects or infection. Spine (Phila Pa 1976) 28:1203-1211, 2003

11. Eshima I, Mathes SJ, Paty P: Comparison of the intracellular bacterial killing activity of leukocytes in musculocutaneous and random-pattern flaps. Plast Reconstr Surg 86:541-547, 1990

12. Foster RD, Anthony JP, Mathes SJ, Hoffman WY: Ischial pressure sore coverage: a rationale for flap selection. Br $\mathbf{J}$ Plast Surg 50:374-379, 1997

13. Garvey PB, Rhines LD, Dong W, Chang DW: Immediate soft-tissue reconstruction for complex defects of the spine following surgery for spinal neoplasms. Plast Reconstr Surg 125:1460-1466, 2010

14. Giesswein P, Constance CG, Mackay DR, Manders EK: Supercharged latissimus dorsi muscle flap for coverage of the problem wound in the lower back. Plast Reconstr Surg 94:1060-1063, 1994

15. Glassman SD, Dimar JR, Puno RM, Johnson JR: Salvage of instrumental lumbar fusions complicated by surgical wound infection. Spine (Phila Pa 1976) 21:2163-2169, 1996

16. Hochberg J, Ardenghy M, Yuen J, Gonzalez-Cruz R, Miura Y, Conrado RM, et al: Muscle and musculocutaneous flap coverage of exposed spinal fusion devices. Plast Reconstr Surg 102:385-392, 1998

17. Hultman CS, Jones GE, Losken A, Seify H, Schaefer TG, Zapiach LA, et al: Salvage of infected spinal hardware with paraspinous muscle flaps: anatomic considerations with clinical correlation. Ann Plast Surg 57:521-528, 2006

18. Inanmaz ME, Kose KC, Isik C, Atmaca H, Basar H: Can hyperbaric oxygen be used to prevent deep infections in neuromuscular scoliosis surgery? BMC Surg 14:85, 2014

19. Khan NR, Thompson CJ, DeCuypere M, Angotti JM, Kalobwe E, Muhlbauer MS, et al: A meta-analysis of spinal surgical site infection and vancomycin powder. J Neurosurg Spine 21:974-983, 2014

20. Klink BK, Thurman RT, Wittpenn GP, Lauerman WC, Cain JE: Muscle flap closure for salvage of complex back wounds. Spine (Phila Pa 1976) 19:1467-1470, 1994

21. Koutsoumbelis S, Hughes AP, Girardi FP, Cammisa FP Jr, Finerty EA, Nguyen JT, et al: Risk factors for postoperative infection following posterior lumbar instrumented arthrodesis. J Bone Joint Surg Am 93:1627-1633, 2011

22. Lantieri LA, Tantaoui B, Rimareix FA, Raulo YF, Baruch JP: Lower back coverage with endoscopically harvested pedicled greater omental flap. Plast Reconstr Surg 103:960-963, 1999

23. Larsson A, Engström M, Uusijärvi J, Kihlström L, Lind F, Mathiesen T: Hyperbaric oxygen treatment of postoperative neurosurgical infections. Neurosurgery 50:287-296, 2002

24. Meiners T, Flieger R, Jungclaus M: Use of the reverse latissimus muscle flap for closure of complex back wounds in patients with spinal cord injury. Spine (Phila Pa 1976) 28:1893-1898, 2003

25. Mericli AF, Tarola NA, Moore JH Jr, Copit SE, Fox JW IV,
Tuma GA: Paraspinous muscle flap reconstruction of complex midline back wounds: Risk factors and postreconstruction complications. Ann Plast Surg 65:219-224, 2010

26. Mitra A, Mitra A, Harlin S: Treatment of massive thoracolumbar wounds and vertebral osteomyelitis following scoliosis surgery. Plast Reconstr Surg 113:206-213, 2004

27. Murphy RC, Robson MC, Heggers JP, Kadowaki M: The effect of microbial contamination on musculocutaneous and random flaps. J Surg Res 41:75-80, 1986

28. O'Shaughnessy BA, Dumanian GA, Liu JC, Ganju A, Ondra SL: Pedicled omental flaps as an adjunct in the closure of complex spinal wounds. Spine (Phila Pa 1976) 32:30743080, 2007

29. Schryvers OI, Stranc MF, Nance PW: Surgical treatment of pressure ulcers: 20-year experience. Arch Phys Med Rehabil 81:1556-1562, 2000

30. Stahl RS, Burstein FD, Lieponis JV, Murphy MJ, Piepmeier JM: Extensive wounds of the spine: a comprehensive approach to debridement and reconstruction. Plast Reconstr Surg 85:747-753, 1990

31. Thalgott JS, Cotler HB, Sasso RC, LaRocca H, Gardner V: Postoperative infections in spinal implants. Classification and analysis - a multicenter study. Spine (Phila Pa 1976) 16:981-984, 1991

32. Vitaz TW, Oishi M, Welch WC, Gerszten PC, Disa JJ, Bilsky $\mathrm{MH}$ : Rotational and transpositional flaps for the treatment of spinal wound dehiscence and infections in patient populations with degenerative and oncological disease. J Neurosurg 100 (1 Suppl Spine):46-51, 2004

33. Zhao J, Li G, Zhang Y, Zhu X, Hou K: Sinking skin flap syndrome and paradoxical herniation secondary to lumbar drainage. Clin Neurol Neurosurg 133:6-10, 2015

\section{Disclosure}

Dr. Levi has financial relationships with Medtronic Sofamor Danek and DePuy Synthes.

\section{Author Contributions}

Conception and design: Chim, Chieng. Acquisition of data: Chim, Chieng, Hubbard, Salgado. Analysis and interpretation of data: Chim, Chieng, Hubbard, Levi. Drafting the article: Chim, Chieng, Hubbard. Critically revising the article: Chim, Chieng, Hubbard, Levi. Reviewed submitted version of manuscript: Chim, Salgado, Levi. Approved the final version of the manuscript on behalf of all authors: Chim. Statistical analysis: Chieng, Hubbard. Study supervision: Chim, Levi.

\section{Correspondence}

Harvey Chim, Division of Plastic Surgery, University of Miami Miller School of Medicine, Clinical Research Bldg., 1120 N.W. 14th St., 4th Fl., Miami, FL 33136. email: harveychim@yahoo. com. 